\title{
Efeito do estádio de maturação dos frutos nas características físico-químicas de acerola(1)
}

\author{
Rejane Jurema Mansur Custódio Nogueira( ${ }^{(2)}$, José Antônio Proença Vieira de Moraes $^{(3)}$, Hélio Almeida Burity ${ }^{(4)}$ \\ e Josué Francisco da Silva Junior(4)
}

\begin{abstract}
Resumo - Este trabalho teve por objetivo avaliar características físico-químicas dos frutos de acerola, em três estádios de maturação. Foram usadas acerolas oriundas de duas matrizes (UFRPE 7 e UFRPE 8), durante as estações seca e chuvosa, num pomar comercial. O delineamento experimental foi o inteiramente casualizado, em esquema fatorial $2 \times 3$ (plantas matrizes x estádios de maturação dos frutos), e três repetições. Foram avaliados os teores de vitamina $\mathrm{C}$ e sólidos solúveis totais ( $\mathrm{SST}$ ), além do $\mathrm{pH}$, do peso e tamanho dos frutos. As aceroleiras UFRPE 7 e UFRPE 8 produziram frutos com teores de vitamina $\mathrm{C}$ adequados tanto para o mercado interno como para o externo. Os frutos verdes apresentaram teores de vitamina $\mathrm{C}$ significativamente maiores que os maduros e semimaduros, podendo ser utilizados pela indústria farmacêutica. Houve influência sazonal nos teores de vitamina C nas características físicas (peso e diâmetros dos frutos) e físico-químicas (SST) das matrizes estudadas. O conteúdo de vitamina $C$ foi mais elevado durante a estação seca, e decresceu com a maturação do fruto. A UFRPE 7 produziu frutos de melhor qualidade, apresentando também maior estabilidade nas características avaliadas do que a UFRPE 8
\end{abstract}

Termos para indexação: Malpighia emarginata, fruto, qualidade, ácido ascórbico.

\section{Physicochemical characteristics of Barbados cherry influenced by fruit maturation stage}

Abstract - This work aimed at evaluating changes in physical and chemical characteristics of Barbados cherry fruits in three maturation stages. Fruits from two genetic sources (UFRPE 7 and UFRPE 8) were used during the dry and wet seasons in a commercial orchard. The experimental design was a completely randomized block with factorial scheme $2 \times 3$ (source plants $\mathrm{x}$ fruit maturation stages) and three replicates. Levels of vitamin $\mathrm{C}$ and of total soluble solids (TSS) besides $\mathrm{pH}$ and fruit weight and diameters were evaluated. Genotypes UFRPE 7 and UFRPE 8 produced fruits containing levels of vitamin $\mathrm{C}$ appropriated to the internal and external markets. Immature fruits showed levels of vitamin $\mathrm{C}$ significantly higher than mature and semi-mature ones. Those fruits could be used in the pharmaceutic industry. Seasonal influence on levels of vitamin C, physical (fruit weight and diameter) and physicochemical (TSS) characteristics were found. Higher levels of vitamin C were observed during the dry season. These contents decreased during the fruit ripening. UFRPE 7 produced the best quality fruits and presented higher stability in most of the characteristics evaluated.

Index terms: Malpighia emarginata, fruit, quality, ascorbic acid.

(1) Aceito para publicação em 27 de julho de 2001

Extraído da tese de doutorado da primeira autora, apresentada à Universidade Federal de São Carlos (UFSCar), São Carlos, SP.

(2) Universidade Federal Rural de Pernambuco, Lab. de Fisiologia Vegetal, Av. D. Manuel de Medeiros, s/n, CEP 52171-900 Recife, PE. E-mail: rmansur@hotlink.com.br

(3) UFSCar, Caixa Postal 676, CEP 13565-905 São Carlos, SP. E-mail: pvmoraes@power.ufscar.br

(4) Empresa Pernambucana de Pesquisa Agropecuária, Caixa Postal 1022, CEP 50761-000 Recife, PE.

E-mail: burity@ipa.br, josuef@ipa.br

\section{Introdução}

A aceroleira, pelo seu inegável potencial como fonte natural de vitamina $\mathrm{C}$ e sua grande capacidade de aproveitamento industrial, tem atraído o interesse dos fruticultores de várias regiões do Brasil. Dado o alto teor de vitamina $\mathrm{C}$ encontrado nos seus frutos, que pode variar de 695 a $4.827 \mathrm{mg} / 100 \mathrm{~g}$ (Asenjo \& Guzman, 1946; Singh-Dhaliwal \& Torres-Sepúlveda, 1962; Medeiros, 1969; Fonseca et al., 1972; Santos et al., 1999; Gomes et al., 2000), a acerola compara-se 
a outras frutas ricas em ácido ascórbico, tais como, camu-camu, rosa-rugosa e cabeludinha, e passou a ter importância econômica em várias regiões, para consumo in natura ou sob a forma de suco, além de ser utilizada também como matéria-prima na indústria farmacêutica e na elaboração de muitos outros subprodutos.

Segundo Machado (1992), há uma tendência em âmbito mundial de aumento do consumo de suco de frutas tropicais; para tanto, é preciso que se tenha um produto de qualidade uniforme, o que atualmente é de difícil obtenção, em virtude de os pomares comerciais, na sua grande maioria, terem sido constituídos por mudas oriundas de sementes. Isso se traduz numa dissociação de caracteres genéticos que culmina com a obtenção de plantas e frutos bastante variáveis em relação aos caracteres físico-químicos.

$\mathrm{O}$ teor de vitamina $\mathrm{C}$ e outras características atribuídas à qualidade da acerola, tais como coloração, peso e tamanho dos frutos, teor de sólidos solúveis totais e $\mathrm{pH}$ do suco, além de serem afetadas pela desuniformidade genética dos pomares, sofrem influência de vários outros fatores, como precipitações pluviais, temperatura, altitude, adubação, irrigação e a ocorrência de pragas e doenças.

Este trabalho teve como objetivo avaliar as características físico-químicas dos frutos de acerola, em três estádios de maturação.

\section{Material e Métodos}

O experimento foi realizado com frutos advindos do pomar comercial Acerolândia, situado no Município de Paudalho, Zona da Mata, Norte de Pernambuco, sob as coordenadas $7^{\circ} 55^{\prime} 58,3^{\prime \prime} \mathrm{S} \mathrm{e} 35^{\circ} 8^{\prime} 12,8^{\prime \prime} \mathrm{W}$ e a uma altitude de $70 \mathrm{~m}$. O clima é quente e úmido, com temperatura e precipitação pluvial médias anuais de $25^{\circ} \mathrm{C}$ e $1.702,1 \mathrm{~mm}$, respectivamente, e meses chuvosos de março a julho (Fundação de Desenvolvimento Municipal do Interior de Pernambuco, 1994) e o solo é do tipo Podzólico Amarelo álico.

A área do pomar foi de aproximadamente 20 ha, com espaçamento entre plantas de $4 \times 5 \mathrm{~m}$, sendo a maioria propagada por meio de sementes, com uma considerável variabilidade fenotípica com relação ao porte, à conformação da copa, à coloração e à morfologia das folhas e dos frutos.

Foram selecionadas as plantas-matrizes UFRPE 7 e UFRPE 8, em função da diferença marcante na morfologia dos frutos: maçã trilobulada e pitanga, respectivamente As matrizes foram plantadas em 1987, utilizando-se mudas obtidas de sementes provenientes da Universidade Federal Rural de Pernambuco (UFRPE). No início do experimento, as matrizes tinham sete anos de idade, as alturas das plantas variaram de 3,20 a $4,10 \mathrm{~m}$; o diâmetro do caule, de 0,38 a 0,49 m; e a projeção da copa variou de 4,50 a $5,30 \mathrm{~m}$.

Os dados foram coletados em duas estações: dezembro de 1994 (estação seca) e julho de 1995 (estação chuvosa). As pluviosidades foram de 12,30 e $217,70 \mathrm{~mm}$; as temperaturas médias, de 26,9 e $24,3^{\circ} \mathrm{C}$, e as umidades relativas do ar, de 73 e $87 \%$, respectivamente, nas estações seca e chuvosa. Adotou-se o delineamento experimental inteiramente casualizado, em esquema fatorial $2 \times 3$ (matrizes $\mathrm{x}$ estádios de maturação dos frutos, respectivamente) e três repetições (três porções de frutos da mesma planta). As variáveis estudadas foram os teores de vitamina $\mathrm{C}$, sólidos solúveis totais (SST) e $\mathrm{pH}$ do suco, cuja unidade experimental constou de uma parcela com aproximadamente $100 \mathrm{~g}$ de frutos, oriundos de uma mesma planta de cada matriz. Quanto às características físicas (peso e tamanho), a unidade experimental constou de uma parcela com 50 frutos em cada tratamento.

$\mathrm{Na}$ classificação dos frutos quanto aos estádios de maturação, foi utilizado o grau de cor da casca, considerando: frutos verdes, os que apresentavam mais que $75 \%$ da casca com coloração verde; frutos semimaduros, os que apresentavam mais que $75 \%$ da casca com coloração alaranjada; frutos maduros, os que apresentavam $100 \%$ da casca com coloração vermelha (UFRPE 7) ou cor de vinho (UFRPE 8).

Nos meses preestabelecidos das estações seca e chuvo$\mathrm{sa}$, os frutos foram colhidos aleatoriamente por toda planta, e separados de acordo com o estádio de maturação, no início da manhã, acondicionados em sacos de polietileno pretos e posteriormente em caixas de isopor, sendo então transportados imediatamente até o Laboratório de Ecofisiologia do Departamento de Biologia da UFRPE, para procedimento das análises. Nesses dias, as plantas apresentavam cargas semelhantes de frutos com diversos estádios de maturação

No laboratório, os frutos foram selecionados, descartando-se os danificados pelo atrito no transporte, os manchados, deformados, com picadas de insetos ou com sintomas de doença. Os frutos sadios (verdes, semimaduros e maduros) foram agrupados em quatro bandejas plásticas devidamente etiquetadas, sendo uma delas destinada para a determinação das características físicas, como peso, diâmetros longitudinal (altura) e transversal (largura), enquanto as três restantes foram utilizadas para análise de vitamina 
C, SST ( ${ }^{\circ}$ Brix) e pH. O peso (g) foi obtido pela pesagem individual de cada fruto; os diâmetros longitudinal e transversal $(\mathrm{mm})$, medidos com auxílio de um paquímetro de aço, modelo Vernier Coliper; para a determinação do teor de vitamina C seguiu-se a metodologia de Tillmmans (1927), modificada por Bezerra Neto et al. (1994). A mesma consta da titulação do ácido ascórbico presente no suco da fruta, utilizando-se uma solução de 2,6-diclorofenolindofenol; usou-se a solução de ácido oxálico como solvente e estabilizadora da vitamina $\mathrm{C}$ (que se comporta como um composto bastante instável), em substituição ao ácido metafosfórico, tradicionalmente utilizado neste método Os SST foram determinados utilizando-se um refratômetro manual (ATTAGO, modelo N1, Tokyo) e o pH, segundo Instituto Adolfo Lutz (1973), utilizando-se potenciômetro com membrana de vidro, Digimed, modelo DMP.

Quanto aos teores de vitamina C e de sólidos solúveis totais (SST) e o $\mathrm{pH}$, os dados foram analisados isoladamente (em cada estação) e conjuntamente, pela análise de variância e correlação, utilizando-se, para comparação das médias, o teste de Tukey a $5 \%$ de probabilidade. Os dados do peso, altura e largura dos frutos, foram analisados pela estatística descritiva, pelo cálculo das médias e seus respectivos desvios-padrões.

\section{Resultados e Discussão}

Houve efeito altamente significativo quanto à época (estação), matrizes, estádios de maturação e à interação época $\mathrm{x}$ matrizes, com relação às variáveis teores de vitamina $\mathrm{C}$ e de SST. Os tratamentos não apresentaram efeito significativo sobre o $\mathrm{pH}$ (Tabela 1).
O conteúdo de vitamina $\mathrm{C}$ decresceu com a maturação do fruto, ou seja, os frutos verdes apresentaram valores superiores aos encontrados nos frutos maduros, independentemente da matriz estudada e da estação climática (Figura 1). Tal fato concorda com os resultados de diversos autores (Asenjo \& Moscoso, 1950; Lopez, 1963; Medeiros, 1969; Carvalho, 1992; Alves, 1993; Santos et al., 1999). Durante a maturação, a concentração dessa vitamina decresceu de 2.626,00 para 1.797,80 mg/100 mL de suco e de $2.576,76$ para $1.561,74 \mathrm{mg} / 100 \mathrm{~mL}$ de suco, na matriz UFRPE 7, ao longo da estação seca e chuvosa, respectivamente. Na UFRPE 8, essa variação situou-se entre $2.732,70$ e $1.682,67 \mathrm{mg} / 100 \mathrm{~mL}$ de suco na estação seca, e entre $1.753,25$ e $865,80 \mathrm{mg} / 100 \mathrm{~mL}$ de suco no período das chuvas.

As perdas de vitamina $\mathrm{C}$ em decorrência do estádio de maturação dos frutos diferiram entre as matrizes e as estações do ano. A UFRPE 8 apresentou maiores perdas, tanto na estação seca $(38,42 \%)$ quanto na chuvosa $(50,62 \%)$, em comparação com a matriz UFRPE 7, cujos valores foram de $31,54 \%$ (estação seca) e de $39,40 \%$ (estação chuvosa). Independentemente da matriz, as maiores perdas ocorreram na estação das chuvas. Segundo Asenjo (1959), Brown (1966), Guadarrama (1984) e Alves (1993), as perdas na concentração de vitamina $\mathrm{C}$ podem atingir valores maiores que $50 \%$. Comparando os dados deste trabalho com outros, podem-se observar essas variações (Tabela 2). Com relação aos frutos ver-

Tabela 1. Síntese da análise de variância conjunta para teor de vitamina C, pH e sólidos solúveis totais (SST) em frutos maduros, semimaduros e verdes de duas matrizes de acerola (UFRPE 7 e UFRPE 8), nas estações seca (Dez. 94) e chuvosa (Jul. 95). Paudalho (PE).

\begin{tabular}{lcccr}
\hline Fontes de variação & Graus de & \multicolumn{3}{c}{ Quadrados médios } \\
\cline { 3 - 5 } & liberdade & Vitamina $C(\mathrm{mg} / 100 \mathrm{~mL}$ de suco $)$ & $\mathrm{pH}$ & SST $(\%)$ \\
\hline Época (E) & 1 & $156,13^{* *}$ & $3,49^{\mathrm{ns}}$ & $739,72^{* *}$ \\
Matriz (M) & 1 & $104,94^{* *}$ & $0,04^{\mathrm{ns}}$ & $8,71^{* *}$ \\
Estádio de maturação (EM) & 2 & $200,19^{* *}$ & $0,87^{\mathrm{ns}}$ & $27,81^{* *}$ \\
E x M & 1 & $85,94^{* *}$ & $3,21^{\mathrm{ns}}$ & $247,41^{* *}$ \\
E x EM & 2 & $0,79^{\mathrm{ns}}$ & $0,41^{\mathrm{ns}}$ & $0,75^{\mathrm{ns}}$ \\
M x EM & 2 & $0,30^{\mathrm{ns}}$ & $0,71^{\mathrm{ns}}$ & $1,29^{\mathrm{ns}}$ \\
E x M x EM & 2 & $1,88^{\mathrm{ns}}$ & $1,34^{\mathrm{ns}}$ & $3,87^{\mathrm{ns}}$ \\
Resíduo & 24 & & & \\
\hline CV $(\%)$ & & 6,10 & 5,14 & 2,98 \\
\hline
\end{tabular}

${ }^{n}$ Não-significativo. ${ }^{* *}$ Significativo a $1 \%$ de probabilidade, pelo teste $\mathrm{F}$. 


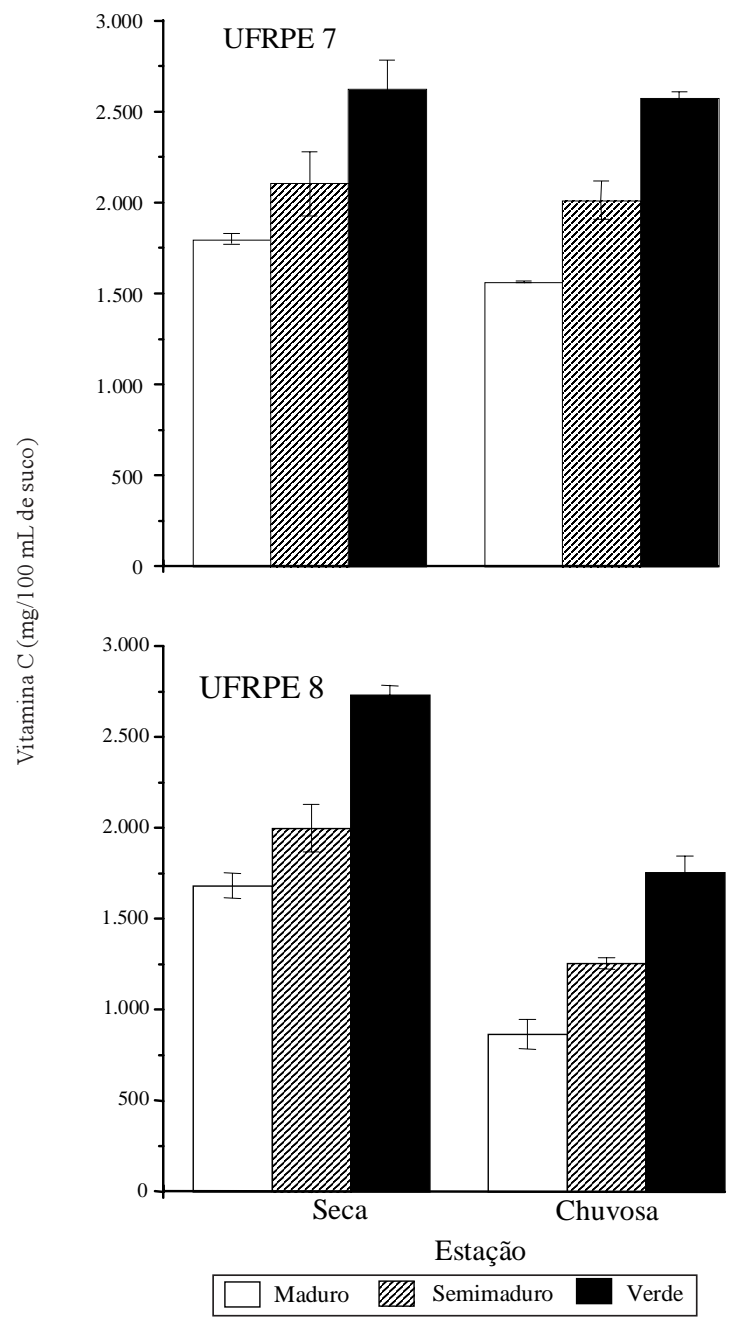

Figura 1. Teores de vitamina $\mathrm{C}$ em frutos de diferentes estádios de maturação, de duas matrizes de acerola (UFRPE 7 e UFRPE 8), nas estações seca (Dez. 94) e chuvosa (Jul. 95). Paudalho, PE. As colunas representam valores médios de três determinações, e as barras, o desvio-padrão. des, os valores obtidos pelas matrizes na estação seca $(2.626,00$ e $2.732,70 \mathrm{mg} / 100 \mathrm{~mL}$ de suco) foram superiores e inferiores aos verificados por diversos autores.

$\mathrm{O}$ conteúdo de vitamina $\mathrm{C}$ na maioria dos frutos tende a diminuir durante o processo de maturação. Butt (1980) atribui este decréscimo à atuação da enzima denominada ácido ascórbico oxidase (ascorbato oxidase), isolada em acerola por Asenjo et al. (1960), os quais verificaram que a atividade enzimática nos frutos maduros é maior que nos verdes, fato que pode explicar as perdas encontradas no decorrer da maturação.

Segundo Nakasone et al. (1966), a síntese e retenção da vitamina $\mathrm{C}$ em acerola são alteradas por diversos fatores. Foi evidenciado, por esses autores, que a concentração dessa vitamina atinge o pico entre o $16^{\circ}$ e o $18^{\circ}$ dia após a abertura das flores. Silva (1994) relatou que o sombreamento reduziu significativamente a produção de vitamina $\mathrm{C}$, e que a exposição direta dos frutos aos raios solares após a colheita por mais de quatro horas causou perdas significativas e mais: que frutos de plantas propagadas assexuadamente apresentavam teores mais elevados que os produzidos por mudas de sementes. Aróstegui \& Pennock (1955) destacaram que o teor de vitamina $\mathrm{C}$ do fruto pode ainda variar em função da época da colheita. Segundo esses mesmos autores, a acerola apresenta um conteúdo médio de vitamina $\mathrm{C}$ de aproximadamente $2 \%$ e um rendimento médio de suco entre 59 e $73 \%$ do seu peso.

As análises estatísticas realizadas isoladamente, em cada estação do ano quanto ao pH e aos SST, revelaram efeito significativo nas matrizes, nos estádios de maturação e na interação entre eles, apenas na estação seca.

Tabela 2. Conteúdo de vitamina $\mathrm{C}$ em acerolas de diferentes estádios de maturação, determinado em diversas pesquisas.

\begin{tabular}{|c|c|c|c|c|}
\hline Local & Madura & Semimadura & Verde & Fonte \\
\hline & -------- & $--(\mathrm{mg} / 100$ & 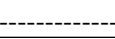 & \\
\hline Brasil (SP) & $1.306,22$ & - & - & Gomes et al. (2000) \\
\hline Brasil (PE) & $2.200,00$ & - & - & Gonzaga Neto et al. (1999) \\
\hline Brasil (BA) & 983,97 & $1.293,98$ & $1.757,64$ & Santos et al. (1999) \\
\hline Brasil (SP) & $1.120,00$ & $1.259,00$ & $1.822,00$ & Alves (1993) \\
\hline Brasil (RS) & $1.123,81$ & $1.559,34$ & $3.175,00$ & Carvalho (1992) \\
\hline Brasil (RJ) & $1.283,00$ & - & $4.827,00$ & Medeiros (1969) \\
\hline Porto Rico & $1.759,00$ & - & $2.802,00$ & Campillo \& Asenjo (1957) \\
\hline Porto Rico & $1.148,00$ & $1.426,00$ & - & Asenjo \& Moscoso (1950) \\
\hline
\end{tabular}


Durante a estação seca, o pH dos frutos maduros foi superior ao encontrado nos verdes (Figura 2). Na matriz UFRPE 8, os valores situaram-se entre 3,49 (maduros) e 3,38 (verdes), enquanto na UFRPE 7, esses variaram de 3,36 a 3,32, respectivamente. Na estação chuvosa, o comportamento foi inverso, ou seja, os frutos verdes apresentaram-se menos
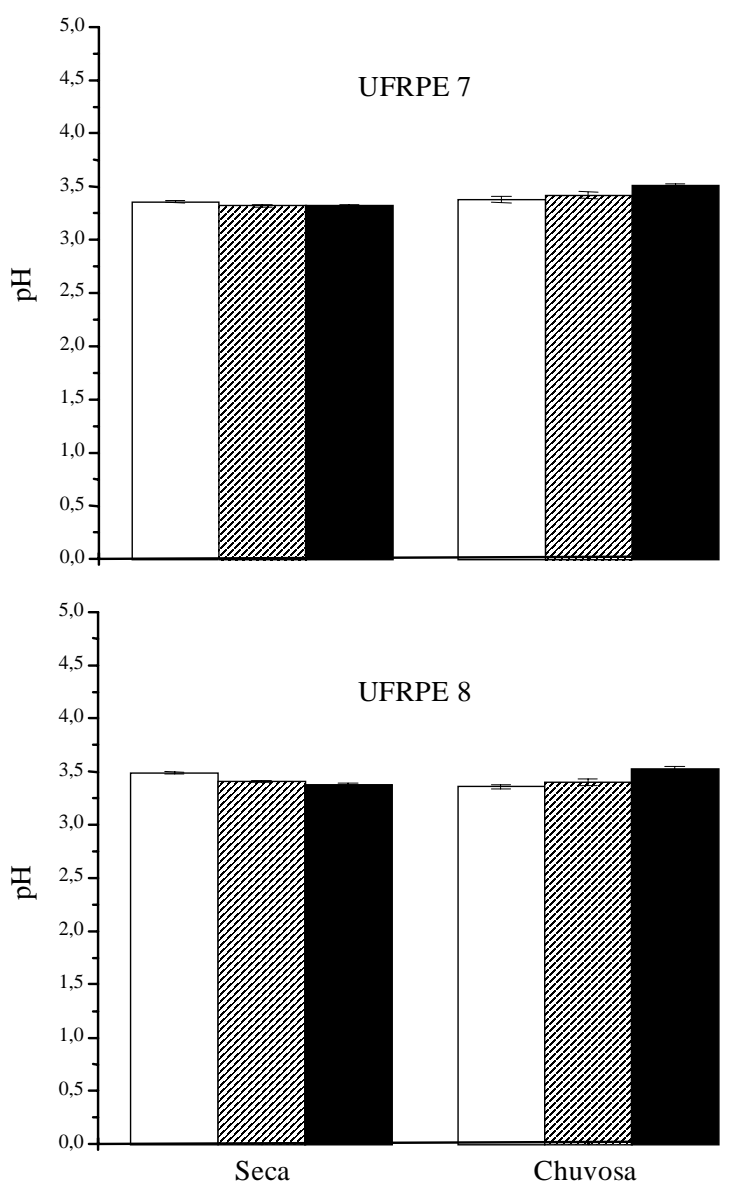

Estação

\section{Maduro $\mathbb{Z I T}$ Semimaduro $\square$ Verde}

Figura 2. $\mathrm{pH}$ em frutos de diferentes estádios de maturação de duas matrizes de acerola (UFRPE 7 e UFRPE 8), nas estações seca (Dez. 94) e chuvosa (Jul. 95). Paudalho, PE. As colunas representam valores médios de três determinações, e as barras, o desvio-padrão. ácidos, com valores de $\mathrm{pH}$ situados entre 3,8 e 3,51 (UFRPE 7), e 3,36 e 3,53 (UFRPE 8), não havendo diferença significativa entre as matrizes (Figura 2). Gomes et al. (2000) encontraram valores situados entre 3,1 e 3,8, enquanto em suco pasteurizado de acerola os valores variaram de 3,5 a 3,7 (Nieva, 1955), inferiores aos obtidos na matriz UFRPE 8. Por outro lado, a variação encontrada por Carvalho (1992) foi de 3,55 a 3,48, superior à registrada na UFRPE 7 . $\mathrm{O}$ aumento do $\mathrm{pH}$ está diretamente relacionado com o decréscimo da acidez ocorrida com o avanço da maturação dos frutos e varia muito pouco no suco de acerola. Corroborando este fato, durante a estação seca foi verificada uma correlação linear negativa entre esta variável e o teor de vitamina $\mathrm{C}\left(\mathrm{r}=-0,5395^{*}\right)$, e uma correlação linear alta e positiva com os $\operatorname{SST}\left(\mathrm{r}=0,9337^{* *}\right)$.

Os teores médios de SST encontrados nos frutos verdes, semimaduros e maduros, durante a estação seca, foram de 7,07, 7,40 e 7,47\% na UFRPE 7, e de $7,80,8,00$ e $8,73 \%$ na UFRPE 8 (Figura 3). Durante a estação chuvosa, esses valores diminuíram mais acentuadamente na matriz UFRPE 8, com mínimos registrados nos frutos verdes de $5,13 \%$.

Os SST têm sido utilizados como índice de maturidade para algumas frutas, como manga, laranja, e outras. Os teores são mais elevados nas acerolas maduras, porém são reduzidos pela chuva ou irrigação excessiva, em virtude da diluição do suco celular, e variam também de acordo com o genótipo. Gomes et al. (2000) encontraram valores médios situados entre 5,25 e $8,58 \%$, cuja variação foi relativa aos genótipos estudados. Fonseca et al. (1972) encontraram um valor médio de $8,0 \%$ de polpa fresca, em acerolas de um pomar de Piracicaba, SP. Em 11 clones estudados por Nakasone et al. (1968), os valores situaram-se entre 6,8 e 11,1\%. Oliveira et al. (2000) observaram em polpas congeladas de acerola uma variação entre 2,32 e 10,4³rix. Alves (1993) reporta que no Nordeste pode-se encontrar valores de $5^{\circ}$ Brix até um máximo de $12^{\circ} \mathrm{Brix}$, com uma média em torno de 7 a $8^{\circ}$ Brix, e os valores baixos foram atingidos por ocasião das chuvas. Dhillon et al. (1990) afirmam que temperaturas médias elevadas e alta luminosidade também aumentam os SST, em razão da maior atividade fotossintética e maior acúmulo de carboidratos nos frutos. 
A exemplo do trabalho realizado por Gerhardt et al. (1997) a baixa precipitação pluvial, ocorrida na estação seca, afetou positivamente a qualidade dos frutos em decorrência da concentração das substâncias. No período que antecedeu a primeira colheita, registrou-se baixa pluviosidade $(12,30 \mathrm{~mm}), 73 \%$ de umidade relativa do ar e temperatura média relativamente elevada $\left(26,9^{\circ} \mathrm{C}\right)$.

$\mathrm{O}$ aumento de peso dos frutos foi progressivo com o avanço da maturação, conforme registrado na literatura (Carvalho, 1992; Santos et al., 1999), e aumentou substancialmente por causa das chuvas (Tabela 3). A matriz UFRPE 7 apresentou em frutos maduros, valores máximos de 7,81 g no período seco, e de 15,02 g, no chuvoso. Na UFRPE 8, os valores médios foram de 6,59 e $10,54 \mathrm{~g}$, respectivamente. Independentemente das matrizes e dos períodos de colheita, o peso médio dos frutos aumentou de 3,94 para $15,02 \mathrm{~g}$, valores estes acima dos obtidos por Carvalho (1992), 2,98 a 5,00 g.

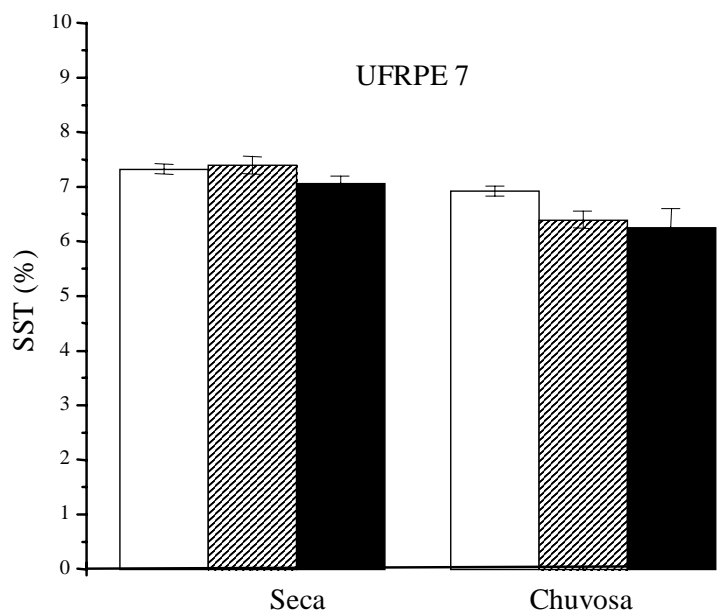

Os dados de peso dos frutos maduros situam-se próximo aos encontrados por Aróstegui et al. (1955), em clones selecionados em Porto Rico, os quais variaram de 7,0 a 12,1 g e superiores aos resultados registrados no Brasil $(2,85 \mathrm{~g}$ a $6,90 \mathrm{~g})$ por Gonzaga Neto et al. (1999), e em Porto Rico (1,7 g a 5,6 g) por Singh-Dhaliwal \& Torres-Sepúlveda (1962), bem como na Índia $(3,3 \mathrm{~g}$ a 5,4 g) por Muthukrishnan \& Palaniswamy (1967).

Os diâmetros dos frutos variaram de maneira semelhante aos do peso (Tabela 3 ). As médias situaram-se entre 18,10 e $25,35 \mathrm{~mm}$ (longitudinal), e entre 20,41 e 29,25 mm (transversal) na matriz UFRPE 7, enquanto na UFRPE 8 esses valores foram de 14,40 a 21,45 mm (longitudinal) e de 15,06 a 27,50 $\mathrm{mm}$ (transversal). Os diâmetros transversais dos frutos maduros (19,10 a 29,2 mm) foram superiores aos verificados em Porto Rico por Singh-Dhaliwal \& Torres-Sepúlveda (1962), em clones selecionados (16,8 a 22,1 mm) e mostrando-se compatíveis com as recomendações do Instituto Brasileiro de Fru$\operatorname{tas}(1995)$.

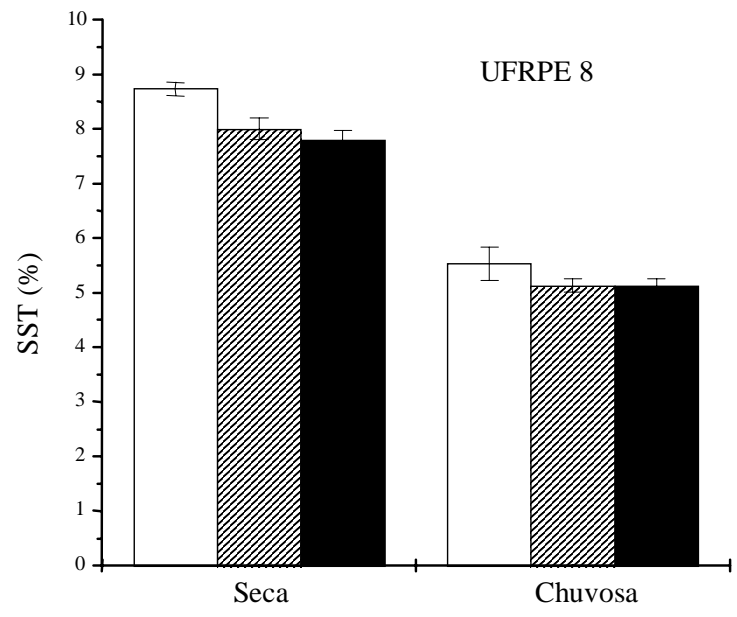

Estação

$\square$ Maduro $\mathbb{Z}$ Semimaduro $\square$ Verde

Figura 3. Teores de sólidos solúveis totais (SST) em frutos de diferentes estádios de maturação, de duas matrizes de acerola (UFRPE 7 e UFRPE 8), nas estações seca (Dez. 94) e chuvosa (Jul. 95). Paudalho, PE. As colunas representam valores médios de três determinações, e as barras o desvio-padrão. 
Tabela 3. Peso, comprimento longitudinal (altura) e comprimento transversal (largura) em frutos maduros, semimaduros e verdes de duas matrizes de acerola, durante as estações seca (Dez. 94) e chuvosa (Jul. 95). Paudalho, PE. Média \pm desviopadrão de 50 frutos

\begin{tabular}{|c|c|c|c|c|}
\hline \multirow[t]{2}{*}{ Estádio de maturação } & \multicolumn{2}{|c|}{ Seca (dezembro/94) } & \multicolumn{2}{|c|}{ Chuvosa (julho/95) } \\
\hline & UFRPE 7 & UFRPE 8 & UFRPE 7 & UFRPE 8 \\
\hline & \multicolumn{4}{|c|}{ Peso $(g)$} \\
\hline Maduros & $7,81 \pm 1,30$ & $6,59 \pm 0,74$ & $15,02 \pm 1,26$ & $10,54 \pm 2,69$ \\
\hline Semimaduros & $5,65 \pm 0,71$ & $5,90 \pm 0,72$ & $12,49 \pm 1,01$ & $9,18 \pm 1,38$ \\
\hline \multirow[t]{2}{*}{ Verdes } & $5,04 \pm 0,10$ & $3,94 \pm 0,26$ & $7,68 \pm 1,07$ & $8,10 \pm 1,05$ \\
\hline & \multicolumn{4}{|c|}{ Comprimento longitudinal (mm) } \\
\hline Maduros & $22,11 \pm 1,04$ & $18,40 \pm 0,97$ & $25,35 \pm 1,19$ & $21,45 \pm 1,56$ \\
\hline Semimaduros & $19,90 \pm 1,09$ & $16,00 \pm 1,05$ & $24,05 \pm 1,02$ & $21,15 \pm 1,28$ \\
\hline \multirow[t]{2}{*}{ Verdes } & $18,10 \pm 1,28$ & $14,40 \pm 1,10$ & $20,06 \pm 0,66$ & $20,45 \pm 0,92$ \\
\hline & \multicolumn{4}{|c|}{ Comprimento transversal (mm) } \\
\hline Maduros & $25,22 \pm 1,21$ & $19,10 \pm 1,32$ & $29,25 \pm 0,97$ & $27,50 \pm 1,70$ \\
\hline Semimaduros & $23,71 \pm 1,15$ & $17,22 \pm 1,43$ & $27,30 \pm 1,49$ & $25,60 \pm 1,47$ \\
\hline Verdes & $20,41 \pm 1,71$ & $15,06 \pm 1,24$ & $22,50 \pm 1,32$ & $24,20 \pm 1,24$ \\
\hline
\end{tabular}

\section{Conclusões}

1. As aceroleiras UFRPE 7 e UFRPE 8 produzem frutos com teores de vitamina $\mathrm{C}$ adequados tanto para o mercado interno como para o externo.

2. Os frutos verdes apresentam teores de vitamina $\mathrm{C}$ significativamente maiores que os maduros $\mathrm{e}$ semimaduros, podendo ser utilizados pela indústria farmacêutica.

3. Há influência sazonal nos teores de vitamina $C$, nas características físicas (peso e diâmetros dos frutos) e físico-químicas (SST) das matrizes estudadas.

4. A UFRPE 7 produz frutos de melhor qualidade, e apresenta também maior estabilidade nas características avaliadas.

\section{Referências}

ALVES, R. E. Acerola (Malpighia emarginata D.C.): fisiologia da maturação e armazenamento refrigerado sob atmosfera ambiente e modificada. 1993. 99 f. Dissertação (Mestrado) - Escola Superior de Agricultura de Lavras, Lavras. 1993.

ARÓSTEGUI, F.; ASENJO, C. F.; MUÑIZ, A. I.; ALEMAÑY, L. Observations and data on a promising selection of the West Indian Cherry, Malpighia punicifolia L. Journal of Agriculture of the University of Puerto Rico, Rio Piedras, v. 39, n. 2, p. 51-56, Apr. 1955
ARÓSTEGUI, F.; PENNOCK, W. La acerola. Rio Piedras: Universidad de Puerto Rico, 1955. 9 p. (Publicación Miscelánea, 15).

ASENJO, C. F. Aspectos químicos y nutritivos de la acerola (Malpighia punicifolia L.). Ciencia, México, v. 19, n. 617, p. 109-118, 1959

ASENJO, C. F.; GUZMAN, S. F. de. The high ascorbic acid content of the West Indian Cherry. Science, Washington, v. 103, p. 219, 1946.

ASENJO, C. F.; MOSCOSO, C. G. Ascorbic acid content and other characteristics of the West Indian Cherry. Food Research, Chicago, v. 15, p. 103-106, 1950

ASENJO, C. F.; PENALOZA, A.; MEDINA, P. Characterization of ascorbase present in the fruit of the Malpighia punicifolia L. Federation of American Societies for Experimental Biology. Federation Proceedings, Bethesda, v. 19, n. 1, p. 1, 1960.

BEZERRA NETO, E.; ANDRADE, A. G. de; BARRETO, L. P. Análise química de tecidos e produtos vegetais. Recife: UFRPE, 1994. 80 p.

BROWN, B. I. Observations on physical and chemical properties of acerola fruits and puree. Queensland Journal of Agricultural and Animal Sciences, Brisbane, v. 23 , p. 599-604, 1966.

BUTT, V. S. Direct oxidases and related enzymes. In STUMPF, P. K.; CONN, E. E. (Ed.). The biochemistry of plants: a comprehensive treatise. New York: Academic, 1980. v. 2, p. 81-123. 
CAMPILLO, A. del; ASENJO, C. F. The distribution of ascorbic acid, dehydroascorbic acid, and diketogulonic acid in the acerola fruit at different stages of development. Journal of Agriculture of the University of Puerto Rico, Rio Piedras, v. 41, p. 161-166, 1957.

CARVALHO, R. I. N. de. Influência do estádio de maturação e de condições de armazenamento na conservação da acerola (Malpighia glabra L.). 1992. $143 \mathrm{f}$ Dissertação (Mestrado) - Universidade Federal do Rio Grande do Sul, Porto Alegre. 1992

DHILLON, B. S.; SINGH, S. N.; KUNDAL, G. S. Studies on the developmental physiology of guava fruit (Psidium guajava L.): II. biochemical characters. Punjab Horticultural Journal, Chandigarh, v. 27, n. 3/4, p. 212221, 1990.

FONSECA, H.; NOGUEIRA, J. N.; LEME JÚNIOR, J Influência de alguns compostos químicos na retenção do ácido ascórbico em frutas liofilizadas. Anais da Escola Superior de Agricultura Luiz de Queiroz, Piracicaba, v. 29 , p. 317-326, 1972.

FUNDAÇÃO DE DESENVOLVIMENTO MUNICIPAL DO INTERIOR DE PERNAMBUCO (Recife, PE). Histórico do Município de Paudalho. In: Perfil municipal do interior de Pernambuco. Recife, 1994. p. 639-642.

GERHARDT, L. B. de A.; MANICA, I.; KIST, H.; SIELER, R. L. Características físico-químicas dos frutos de quatro cultivares e três clones de goiabeira em Porto Lucena, RS Pesquisa Agropecuária Brasileira, Brasília, v. 32, n. 2, p. 185-192, fev. 1997

GOMES, E.; DILERMANDO, P.; MARTINS, A. B. G.; FERRAUDO, A. S. Análise de grupamentos e de componentes principais no processo seletivo em genótipos de aceroleira (Malpighia emarginata DC). Revista Brasileira de Fruticultura, Jaboticabal, v. 22, n. 1, p. 36-39, abr. 2000

GONZAGA NETO, L.; MATTUZ, B.; SANTOS, C. A. F. Caracterização agronômica de clones de aceroleira (Malpighia spp.) na região do submédio São Francisco. Revista Brasileira de Fruticultura, Jaboticabal, v. 21, n. 2, p. 110-115, ago. 1999.

GUADARRAMA,A. S. Algunos cambios químicos durante la maduración de frutos de semeruco (Malpighia punicifolia L.). Revista de la Facultad de Agronomía, Maracay, v. 13, n. 1/4, p. 111-128, 1984.

INSTITUTO ADOLFO LUTZ (São Paulo, SP). Normas analíticas, métodos químicos e físicos para análise de alimentos. São Paulo, 1973. v. 1.

INSTITUTO BRASILEIRO DE FRUTAS (São Paulo, SP). Normas soluções fruta a fruta: acerola. São Paulo, 1995. $59 \mathrm{p}$
LOPEZ,A. P. Relation of maturity to some fruit characters of the West Indian Cherry. Journal of Agriculture of the University of Puerto Rico, Rio Piedras, v. 47, n. 3, p. 193 200, 1963

MACHADO, U. D. Nordeste-EMBRAPA: relatório: avaliação e proposições. Brasília: Sinpaf, 1992. 321 p.

MEDEIROS, R. B. de. Teores de ácido ascórbico, ácido dehidroascórbico e ácido diquetogulônico na acerola (Malpighia glabra L.) verde e madura. Revista Brasileira de Medicina, São Paulo, v. 26, n. 7, p. 398-400, 1969.

MUTHUKRISHNAN, C. R.; PALANISWAMY, K. P. Studies on the utilization of West Indian Cherry (Malpighia punicifolia L.) for the preparation of certain edible products. South Indian Horticulture, New Delhi, v. 15, p. 58-63, 1967.

NAKASONE, H. Y.; MIYASHITA, R. K.; YAMANE, G. M. Factors affecting ascorbic acid content of the acerola (Malpighia glabra L.). Proceedings of the American Society for Horticultural Science, Alexandria, v. 89, p. 161-166, 1966.

NAKASONE, H. Y.; YAMANE, G. M.; MIYASHITA, R. K. Selection, evaluation and naming of acerola (Malpighia glabra L.) cultivars. Honolulu: University of Hawaii, 1968. 19 p. (Circular, 65)

NIEVA, F. S. Extraction, processing, canning and quality of acerola juice. Journal of Agriculture of the University of Puerto Rico, Rio Piedras, v. 39, n. 4, p. 175-183, 1955.

OLIVEIRA, M. O. B.; FEITOSA, T.; BASTOS, M. S. R.; BRANCO, M. A. A. C.; SILVA, M. G. G. Perfil químico de qualidade das polpas de acerola, cajá e caju comercializadas no Estado da Bahia. Revista Brasileira de Fruticultura, Jaboticabal, v. 22, p. 9-15, jul. 2000. Número especial.

SANTOS, A. R. L.; REINHARDT, D. H.; SILVEIRA, W. R.; OLIVEIRA, J. R. P.; CALDAS, R. C. Qualidade pós-colheita de acerola para processamento, em função de estádios de maturação e condições de armazenamento. Revista Brasileira de Fruticultura, Jaboticabal, v. 21, n. 3, p. 365-371, dez. 1999

SILVA, J. J. M. Fatores que afetam o conteúdo do ácido ascórbico da acerola (Malpighia glabra L.). São Luís Secretaria Municipal de Produção e Abastecimento, 1994 23 p. (Cadernos de Agricultura, 1)

SINGH-DHALIWAL, T.; TORRES-SEPÚLVEDA, A . Performance of acerola, Malpighia punicifolia L., in the coffee region of Puerto Rico. Journal of Agriculture of the University of Puerto Rico, Rio Piedras, v. 46, n. 3, p. 195-204, July 1962. 